\title{
Get Your Project Funded: Using Biometric Data to Understand What Makes People Trust and Support Crowdfunding Campaigns
}

\author{
Mhairi McNeill \\ Edinburgh Napier University \\ Edinburgh, UK \\ m.mcneill2@napier.ac.uk
}

\author{
Alistair Lawson \\ Edinburgh Napier University \\ Edinburgh, UK \\ a.lawson@napier.ac.uk
}

\author{
Robert Raeside \\ Edinburgh Napier University \\ Edinburgh, UK \\ r.raeside@napier.ac.uk
}

\author{
Tom Peisl \\ Munich University of Applied \\ Sciences \\ Munich, Germany \\ tompeisl@me.com
}

\begin{abstract}
Creating a good crowdfunding campaign is difficult. By understanding why people contribute to crowdfunding campaigns we can make campaigns better and raise more money. Crowdfunding websites allow entrepreneurs to make a pitch, which is watched by potential funders. This article describes a pilot of an experiment that measures how people react to both successful and unsuccessful pitches. In particular we are interested in emotional reactions and trust reactions. Unexpectedly, failed campaigns were watched more and were judged to have higher integrity. Perceived ability seemed to be the best predictor of a campaign's success. We hope to explore this subject in more depth with further experiments.
\end{abstract}

Keywords: Entrepreneurial fund raising, Biometric measurement, Evaluation, Crowdfunding

\section{INTRODUCTION}

\subsection{Our Study}

\subsubsection{What have we done?}

We wanted to understand the difference between successful and unsuccessful crowdfunding campaigns. We did this by tracking the eye movements and facial expressions of people watching crowdfunding campaign videos. We also asked our participants to answer a series of questions about each video.

There is evidence to suggest that crowdfunding success is related to feelings of trust (Shpynov, 2015). Our questions were designed to measure the elements of trust from a model proposed by Mayer et al. (1995).

Gaining a better understanding of what makes a successful campaign has clear benefits to the entrepreneur seeking to raise money from crowdfunding. We also think this research could enhance the reputation of the platform and the intrinsic rewards to the viewer. We believe that using a combination of eye tracking and facial expression analysis is a useful and effective method for understanding how decisions are made on websites in general.

\subsection{Crowdfunding}

\subsubsection{What is crowdfunding?}

Crowdfunding is a way of raising money for a business venture or charitable cause. It is different from more traditional forms of funding because it seeks relatively small amounts of money from a large number of people. Crowdfunding is normally conducted though websites (Crosetto \& Regner, 2014).

This study focuses on crowdfunding campaigns from the website Kickstarter, a platform for reward based crowdfunding. In reward based crowdfunding, money is given to the campaign in return for potential future rewards. Often the reward is a final product that is going to be manufactured; so this type of crowdfunding can be thought of as pre-selling.

Kickstarter is currently the largest crowdfunding site (Mollick, 2014). However, we believe these results could apply across different crowdfunding sites and different forms of crowdfunding.

\subsubsection{Why is crowdfunding important?}

Crowdfunding has been growing, and subsequently it is becoming an increasingly common way for new ventures to be funded. In 2016 the reward based crowd-funding market in Europe was worth $€ 190$ million, up from $€ 63$ million in 2013 (Zhang et al., 2017). 
Kickstarter in particular is a huge source of funding. As of March 2018, over \$3 billion has been raised to fund successful projects on Kickstarter (“Kickstarter Stats - Kickstarter," n.d.).

\section{LITERATURE REVIEW}

\subsection{Predicting Crowdfunding success}

The literature on predicting success in crowdfunding is extensive. Several features common to successful campaigns were found repeatedly throughout the literature:

- Being featured on the crowdfunding site (Mitra \& Gilbert, 2014; Mollick, 2014).

- Frequently updating backers on the status of the product (Crosetto \& Regner, 2014; Mitra \& Gilbert, 2014; Mollick, 2014).

- Having a pitch video (Crosetto \& Regner, 2014; Mitra \& Gilbert, 2014; Mollick, 2014)

- Having a high number of pledges near the start of the campaign (Crosetto \& Regner, 2014; Etter, Grossglauser, \& Thiran, 2013; Li, Rakesh, \& Reddy, 2016).

- Having a small funding goal (Crosetto \& Regner, 2014; Mollick, 2014).

- Having a short campaign duration (Crosetto \& Regner, 2014; Mitra \& Gilbert, 2014; Mollick, 2014).

- Giving rewards which pre-sell the product (Crosetto \& Regner, 2014; Forbes \& Schaefer, 2017).

- The entrepreneurs behind the campaign having lots of social network connections (Crosetto \& Regner, 2014; Mollick, 2014).

Mollick (2014) also found successful campaigns tended to have fewer spelling errors. Crosetto and Regner (2014) noted that successful campaigns had more images and tended to give rewards that offer social reputation. Forbes and Schaefer (2017) found that videos that were short and were front loaded with a plan were more likely to be successful. One paper (Mitra \& Gilbert, 2014) looked at which categories of campaign did well. They found the most successful campaigns tended to be in one of the following categories: graphic design, theatre, games, web series, animation, food, documentary, art, board and card games, fashion and periodical. Unsuccessful campaigns were more likely to be in pop, performance art, children's books, country and folk, public art, short film, journalism, rock, film and video, mixed media, music and electronic music. Kuppuswamy \& Bayus (2015) found that having a lot of other campaigns currently on the crowdfunding platform often corresponded with lower levels of success for each campaign, presumably due to the high levels of competition.

\subsection{Models of trust}

There is little work that looks at the relationship between crowdfunding and trust. In particular, we found no work which focused on crowdfunding and trust using biometric data.

We used a trust model from Mayer, Davis, and Schoorman (1995) as a base to investigate the role of trust. A summary of this is displayed in Figure 1. Importantly for this study it proposes that trust is caused by ability, benevolence and integrity.

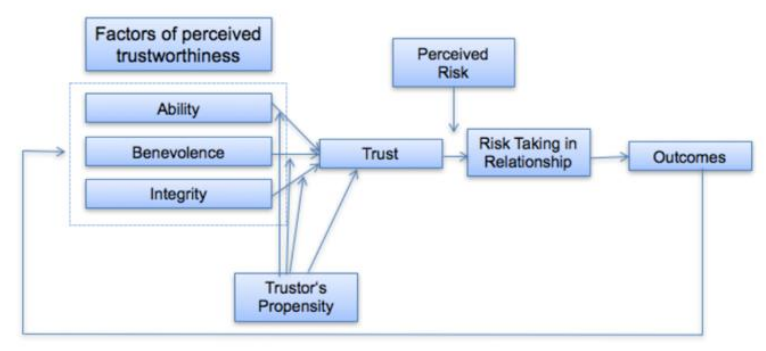

Figure 1 Model of trust from Mayer, Davis and Schoorman (1995)

\section{METHOD}

Our pilot study comprised of 6 volunteers, who each watched 11 videos from crowdfunding campaigns. The campaigns were sampled by taking the first 5 successful and first 6 unsuccessful campaigns with videos from the 'almost finished' section of Kickstarter's 'Food and Drink' category.

The respondents were shown an edited version of Kickstarter's campaign page, which showed only the campaign video, campaign title and the amount of money the campaigned wished to raise. The order of the campaigns was randomised.

While each participant looked at the campaign pages and watched the accompanying videos, we used the iMotions (2015) software to identify which part of the screen their eyes focused on, and the facial expressions they made whilst watching the videos.

After each video a short questionnaire was presented on the screen. It included the following four questions:

(i) On a scale of 1 to 10 , what do you think the chances are of this particular project succeeding? ( 1 is a low chance of success, 10 is a high chance).

(ii) On a scale of 1 to 10 , how much of the video do you believe? ( 1 is I don't believe anything in the video, 10 is I believe everything in the video).

(iii) On a scale of 1 to 10 , how much do you think the people behind the project care 
Mhairi McNeill • Alistair Lawson • Robert Raeside • Tom Peisl

about the funders of the project? ( 1 is don't care, 10 is care very much).

(iv) On a scale of 1 to 10 , how likely would you be to back this project financially? (10 is very likely, 1 is very unlikely).

Questions (i), (ii), (iii) were designed to measure ability, integrity and benevolence, as per the model of trust described in Mayer et al. (1995).

The results were analysed using the $R$ statistical programming language (R Core Team, 2016). The plots in this report were produced using the ggplot2 library (Wickham, 2009) and analysis was done using the tidyverse range of packages (Wickham, 2016).

\section{RESULTS SO FAR}

\subsection{Facial Tracking results}

We found some interesting patterns in the facial expressions people displayed. When subjects watched successful crowdfunding campaigns they demonstrated higher average joy scores. Also surprise was more commonly and more strongly registered when watching successful campaigns. Disgust on the other hand showed the opposite pattern; during successful campaigns there was a lower average disgust score. These results are shown in Table 1 and Figure 2. We also measured facial expressions of anger, fear and sadness. However, there were only very small differences in the scores shown between the two video types.

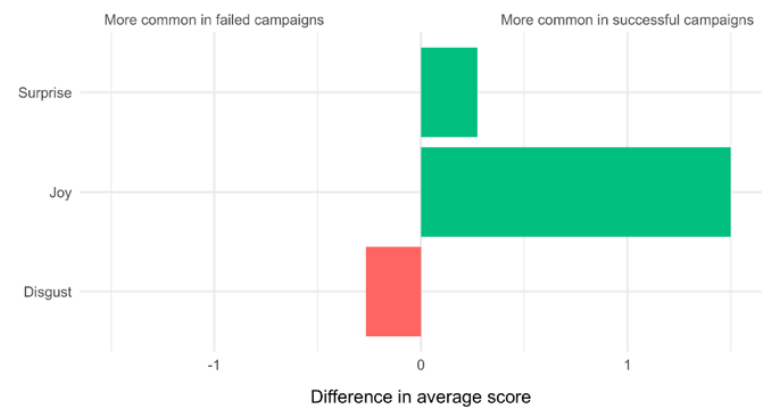

Figure 2 The difference in average emotion scores expressed during successful and unsuccessful campaigns.

Table 1 This table shows the average score for our three emotions in both successful and unsuccessful campaigns.

\begin{tabular}{|l|l|l|l|}
\hline Emotion & $\begin{array}{c}\text { Average } \\
\text { score in } \\
\text { failed } \\
\text { campaigns }\end{array}$ & $\begin{array}{c}\text { Average } \\
\text { score in } \\
\text { successful } \\
\text { campaigns }\end{array}$ & Difference \\
\hline Disgust & 1.7 & 1.4 & -0.3 \\
\hline Joy & 3.3 & 4.8 & 1.5 \\
\hline Surprise & 0.9 & 1.1 & 0.3 \\
\hline
\end{tabular}

None of these differences reached the threshold of statistical significance. Presented in Table 2 are pvalues from a Welch Two Sample t-test for the difference between two means for each of the three emotions.

Table $2 P$-values from a t-test for the difference in emotion expressed in unsuccessful and successful campaigns.

\begin{tabular}{|l|l|}
\hline Emotion & P-Value \\
\hline Joy & 0.556 \\
\hline Disgust & 0.591 \\
\hline Surprise & 0.504 \\
\hline
\end{tabular}

\subsection{Time spent viewing videos}

We purposely let the respondents watch as much or as little of the video as they liked. We expected that the successful campaign's videos would be more engaging and would result in a higher percentage of the video being watched. However, we found the opposite was true.

We calculated 'percent of video watched' by dividing the length of time spent on a campaign's page by the length of the video. Many people watched the whole video and spent some time reading the title and the goal, so had a 'percent of video watched' greater than a $100 \%$.

Figure 3 shows two histograms, one for successful campaigns and one for failed campaigns. One can see that the videos for failed campaigns had a much higher proportion of people staying for the full length of the video and longer. Indeed, for failed campaigns the participants stayed on the campaign page for $111 \%$ of the video duration on average, while for successful campaigns the average duration on the page was only $70 \%$ of the video length. There is very good evidence that this is a real difference (t-test $\mathrm{p}$-value $=<0.001)$.

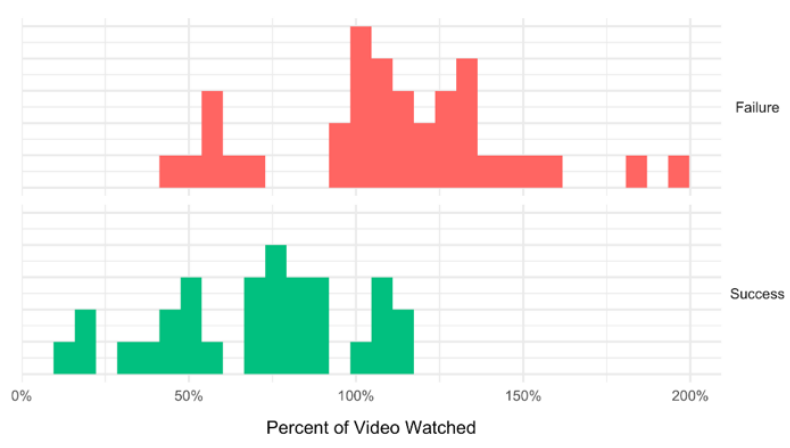

Figure 3 The percentage of each video each respondent watched among the failed campaigns. The lower histogram shows the same among the successful campaigns.

However, successful videos are longer on average, which may explain the difference. Table 3 shows the average length of videos from the successful 
Mhairi McNeill • Alistair Lawson • Robert Raeside • Tom Peisl

campaigns and the unsuccessful campaigns. The successful campaign videos are almost twice as long on average.

Table 3 Average video length for successful and unsuccessful campaigns.

\begin{tabular}{|l|l|}
\hline Campaign & Average video length (minutes) \\
\hline Failure & $1: 34$ \\
\hline Success & $3: 05$ \\
\hline
\end{tabular}

\subsection{Survey responses}

\subsubsection{Trust model}

There were significant differences in how people answered the questions at the end of the videos. We expected that all the questions that related to the trust model would have higher scores in the successful video; this would fit with the hypothesis that trust leads to successful campaigns. However, as can be seen in Table 4 and Figure 4, we tended to see lower values in successful videos for the integrity and benevolence questions.

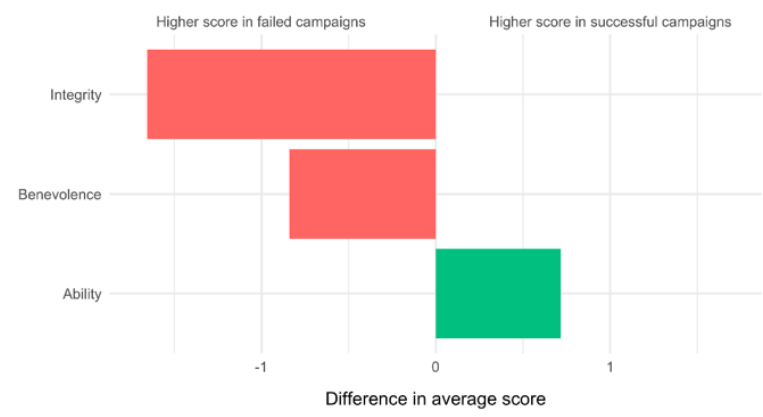

Figure 4 - Difference in average scores for trust model questions

It seems that successful campaigns were more convincing about their ability to succeed. But our respondents actually found there was more integrity and benevolence shown in the unsuccessful videos.

Table 4 Average scores given for trust model questions.

\begin{tabular}{|l|l|l|l|}
\hline Question & $\begin{array}{c}\text { Score in } \\
\text { failed } \\
\text { campaigns } \\
\text { (out of 10) }\end{array}$ & $\begin{array}{c}\text { Score in } \\
\text { successful } \\
\text { campaigns } \\
\text { (out of 10) }\end{array}$ & Difference \\
\hline Ability & 3.9 & 4.6 & 0.7 \\
\hline Benevolence & 5.6 & 4.8 & -0.8 \\
\hline Integrity & 7.1 & 5.4 & -1.7 \\
\hline
\end{tabular}

Shown in Table 5 are the p-values for three t-tests for the difference between two means. For the question about integrity we have good evidence at the $5 \%$ level that scores were different between successful and unsuccessful campaigns. However, for the other two questions we do not meet that level of evidence.
Table 5 P-values from a two-sample t-test, that tested whether the scores given for each question were different in unsuccessful and successful campaigns

\begin{tabular}{|l|l|}
\hline Question & P-Value \\
\hline Ability & 0.183 \\
\hline Benevolence & 0.052 \\
\hline Integrity & 0.019 \\
\hline
\end{tabular}

4.3.2 Would you financially support this campaign? As an interesting side note, there is no evidence that our participants can predict which projects will succeed ( $p$-value $=0.394)$. Shown in Figure 5 are the responses to the question 'would you financially support this campaign?'. Successful campaigns scored an average of 1.6 out of 10 while unsuccessful campaigns scored marginally more with an average of 1.9 .

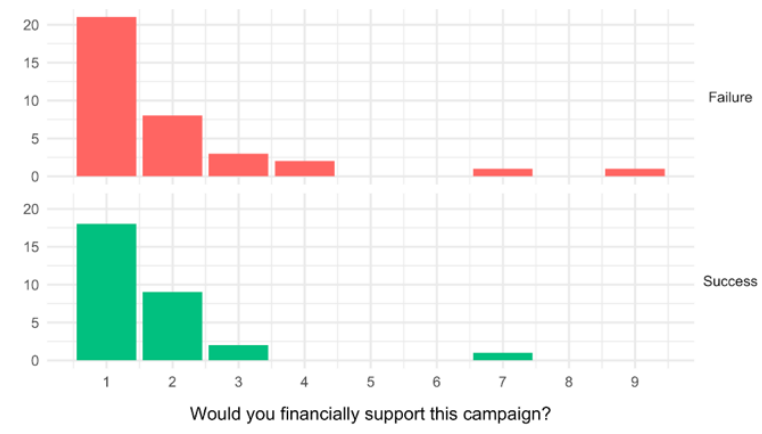

Figure 5 Answers to the question 'Would you financially support this campaign?' for both successful and failing campaigns.

\section{CONCLUSIONS}

We have obtained some very interesting initial results from a pilot study. However, we are still lacking data to say with confidence what predicts a campaigns success. Next we will conduct a full study with 18 participants, in which we will ensure a similar average length of video in successful and unsuccessful campaigns.

We found the results about integrity and benevolence very interesting and believe that trust may be a poor model for understanding crowdfunding decision making. It seems that the main driver of funding is the perceived ability of the project creators.

\section{REFERENCES}

Crosetto, P., \& Regner, T. (2014). Crowdfunding: Determinants of success and funding dynamics. Jena Economic Research Papers, 2014-2035. https://doi.org/10.1007/s10273011-1262-2 
Etter, V., Grossglauser, M., \& Thiran, P. (2013). Launch hard or go home! Proceedings of the First ACM Conference on Online Social Networks - COSN '13, 177-182. https://doi.org/10.1145/2512938.2512957

Forbes, H., \& Schaefer, D. (2017). Guidelines for Successful Crowdfunding. Procedia CIRP, 60, 398-403.

https://doi.org/10.1016/j.procir.2017.02.021

iMotions. (2015a). iMotions - Emotient Module: Facial Expression Analysis. Retrieved from http://imotionsglobal.com/software/add-onmodules/attention-tool-facet-module-facialaction-coding-system-facs/

iMotions. (2015b). iMotions - Mobile Eye Tracking Software. Retrieved from http://imotionsglobal.com/software/add-onmodules/mobile-eye-tracking-module-glasses/

Kickstarter Stats - Kickstarter. (n.d.). Retrieved March 21, 2018, from https://www.kickstarter.com/help/stats

Kuppuswamy, V., \& Bayus, L. B. (2015). CROWDFUNDING CREATIVE IDEAS: THE DYNAMICS OF PROJECT BACKERS IN KICKSTARTER Venkat. https://doi.org/10.2139/ssrn.2234765

Li, Y., Rakesh, V., \& Reddy, C. K. (2016). Project Success Prediction in Crowdfunding Environments. Proceedings of the Ninth ACM International Conference on Web Search and Data Mining - WSDM '16, 247-256. https://doi.org/10.1145/2835776.2835791

Mayer, R. C., Davis, J. H., \& Schoorman, F. D. (1995). An Integrative Model of Organizational Trust. Source: The Academy of Management Review, 20(3), 709-734. Retrieved from http://www.jstor.org/stable/258792
Mitra, T., \& Gilbert, E. (2014). The language that gets people to give. Proceedings of the 17th ACM Conference on Computer Supported Cooperative Work \& Social Computing CSCW'14, 49-61. https://doi.org/10.1145/2531602.2531656

Mollick, E. (2014). The dynamics of crowdfunding: An exploratory study. Journal of Business Venturing, 29(1), 1-16. https://doi.org/10.1016/j.jbusvent.2013.06.005

R Core Team. (2016). R: A language and environment for statistical computing. Vienna, Austria: R Foundation for Statistical Computing. Retrieved from https://www.rproject.org/

Shpynov, A. (2015). Influence of emotions on willingness to donate money on crowdfunding Evidence on Kickstarter.

Wickham, H. (2009). Ggplot2. Elegant Graphics for Data Analysis. https://doi.org/10.1007/978-0387-98141-3

Wickham, H. (2016). tidyverse: Easily Install and Load "Tidyverse" Packages. R package version 1.0.0. Retrieved from https://cran.rproject.org/package=tidyverse

Zhang, B., Ziegler, T., Shneor, R., Garvey, K., Wenzlaff, K., Yerolemou, N., \& Hao, R. (2017). Expanding Horizons: The 3rd European alternative finance industry report. University of Cambridge. Retrieved from https://www.jbs.cam.ac.uk/facultyresearch/centres/alternativefinance/publications/expandinghorizons/\#.WrJYJpPFJWM 